\title{
Relationship between Cold Tolerance during Seed Germination and Vegetative Growth in Tomato: Germplasm Evaluation
}

\author{
M.R. Foolad ${ }^{1}$ and G.Y. Lin ${ }^{2}$ \\ Department of Horticulture, 103 Tyson Building, The Pennsylvania State University, University Park, \\ PA 16802
}

\begin{abstract}
AdDITIONAL INDEX WORDs. Lycopersicon sp., abiotic stress, breeding, chilling tolerance, germplasm, seed germination, stress
\end{abstract} tolerance

\begin{abstract}
Cold tolerance (CT) of 31 tomato accessions (cultivars, breeding lines, and plant introductions) representing six Lycopersicon $\mathbf{L}$. sp. was evaluated during seed germination and vegetative growth. Seed germination was evaluated under temperature regimes of $11 \pm 0.5{ }^{\circ} \mathrm{C}$ (cold stress) and $20 \pm 0.5{ }^{\circ} \mathrm{C}$ (control) in petri plates containing $0.8 \%$ agar medium and maintained in darkness. Cold tolerance during seed germination was defined as the inverse of the ratio of germination time under cold stress to germination time under control conditions and referred to as germination tolerance index $\left(\mathbf{T I}_{\mathrm{G}}\right)$. Across accessions, $\mathrm{TI}_{\mathrm{G}}$ ranged from 0.15 to 0.48 indicating the presence of genotypic variation for $\mathrm{CT}$ during germination. Vegetative growth was evaluated in growth chambers with $12 \mathrm{~h}$ days/12 h nights of $12 / 5{ }^{\circ} \mathrm{C}$ (cold stress) and $25 / 18{ }^{\circ} \mathrm{C}$ (control) with a $12 \mathrm{~h}$ photoperiod of $350 \mathrm{mmol} . \mathrm{m}^{-2} \cdot \mathrm{s}^{-1}$ (photosynthetic photon flux). Cold tolerance during vegetative growth was defined as the ratio of shoot dry weight $(\mathrm{DW})$ under cold stress $\left(D W_{\mathrm{S}}\right)$ to shoot $\mathrm{DW}$ under control $\left(\mathrm{DW} \mathrm{W}_{\mathrm{C}}\right)$ conditions and referred to as vegetative growth tolerance index $\left(\mathrm{TI}_{\mathrm{VG}}\right)$. Across accessions, $\mathrm{TI}_{\mathrm{VG}}$ ranged from 0.12 to 0.39 indicating the presence of genotypic variation for $\mathrm{CT}$ during vegetative growth. Cold tolerance during vegetative growth was independent of plant vigor, as judged by the absence of a significant correlation $(r=0.14, P>0.05)$ between $\mathrm{TI}_{\mathrm{VG}}$ and $\mathrm{DW}_{\mathrm{C}}$. Furthermore, CT during vegetative growth was independent of $C T$ during seed germination, as judged by the absence of a significant rank correlation $\left(r_{R}=0.14, P>0.05\right)$ between $\mathrm{TI}_{\mathrm{VG}}$ and $\mathrm{TI}_{\mathrm{G}}$. A few accessions, however, were identified with $\mathrm{CT}$ during both seed germination and vegetative growth. Results indicate that for CT breeding in tomato, each stage of plant development may have to be evaluated and selected for separately.
\end{abstract}

Most commercial cultivars of tomato (Lycopersicon esculentum Mill.) are sensitive to chilling temperatures $\left(0\right.$ to $\left.15^{\circ} \mathrm{C}\right)$ during all stages of plant development, including seed germination, vegetative growth and reproduction (Graham and Patterson, 1982; Lyons, 1973; Lyons et al., 1979; Patterson et al., 1978, 1987). Many tomato production areas in the United States and elsewhere experience low (chilling) temperatures during periods of the growing season. Low temperature (cold stress) sensitivity of commercial tomato cultivars limits geographic distribution of tomato cultivation and the time of year for planting. Cold stress adversely affects plant growth and development throughout the ontogeny of the tomato plant. During seed germination, for example, it delays the onset, reduces the rate, and increases the dispersion of germination events, resulting in poor stand establishment and crop performance. At later stages, cold stress results in reduced plant growth and development, poor flower development and fruit set, and substantial reduction in fruit yield. One approach to minimizing deleterious effects of cold stress is to develop cold-tolerant cultivars. Considerable genetic variation for cold tolerance (CT) exists within and between species of tomato (Cannon et al., 1973; DeVos et al., 1981; El-Sayed and John, 1973; Graham and Patterson, 1982; Ng and Tigchelaar, 1973; Patterson et al., 1978, 1987; Scott and Jones, 1982, 1985, 1986; Smith and

Received for publication 25 Feb. 2000. Accepted for publication 29 July 2000. Contribution 399 of the Department of Horticulture, The Pennsylvania State University. Financial support from the College of Agricultural Sciences, the Pennsylvania State University, and the Pennsylvania Vegetable Marketing and Research Program is appreciated. We thank Professors Paul Grun and William Lamont for reviewing the manuscript before submission. The cost of publishing this paper was defrayed in part by the payment of page charges. Under postal regulations, this paper therefore must be hereby marked advertisement solely to indicate this fact.

${ }^{1}$ Associate professor; corresponding author, e-mail mrf5@psu.edu.

${ }^{2}$ Research assistant.
Millet, 1964; Vallejos, 1979). Such genetic variation is potentially useful for development of tomato cultivars with improved CT.

Cold tolerant tomatoes may have improved earliness, adaptability, water use, and yield of high-quality fruit when grown under suboptimal temperatures. Cold tolerant cultivars could be planted early and harvested early when the crop may have higher economic value. Also, the crop could be grown in the field for longer periods of time (i.e., extended growing season) with total yield being higher. Likewise, production may be improved because early plantings would avoid high temperatures, which can reduce fruit set during midsummer. Furthermore, CT may result in water savings in areas with a Mediterranean climate, because early plant growth makes better use of early-season rains and available water in the root zone.

Under low temperatures, cold tolerant plants grow more rapidly at early stages and thus become established faster than cold sensitive plants. This can have several advantages, including better competition with weeds for water and mineral nutrients and the possibility of earlier application of herbicides. In addition, chilling tolerant plants may outgrow injury caused by insects such as Colorado potato beetle (Leptinotarsa decemlineata Say) which can cause defoliation soon after field transplantation. Moreover, cultivars that germinate and grow rapidly under low temperatures may facilitate local production of transplants in temperate and cool season locations, thus eliminating the need for importation of transplants from warmer locations or production of transplants in heated greenhouses.

A cold-tolerant tomato cultivar should have the ability to germinate rapidly and uniformly, grow efficiently, produce flowers, and set fruit at low temperatures. In spite of extensive research on tomato CT (Dahal and Bradford, 1990; DeVos et al., 1982; Dickson and Petzoldt, 1987; Foolad and Lin, 1998; Foolad et al., 1998; Lyons, 1973; Patterson et al., 1978; Vallejos, 1979; Wolf et al., 1986), little 
attention has been paid to the relationship between CT at different developmental stages. Most of the previous investigations focused only on individual stages. A few studies that included more than one stage, however, evaluated only a few genotypes and thus no definitive conclusions could be drawn regarding the relationship between CT at different stages. Therefore, the objectives of this investigation were to examine the phenotypic relationship between CT during seed germination and vegetative growth in tomato and identify accessions with CT during both stages.

\section{Materials and Methods}

Plant material. Tomato accessions (cultivars, breeding lines, and plant introductions) that were used in this study together with their species name and geographic origin are listed in Table 1. These accessions were chosen mainly based on previous information on their geographic origin (e.g., altitude of the native origin), cold tolerance, or other horticultural characteristics. Original seeds were received from the U.S. Department of Agriculture Plant Genetic Resources Unit, Geneva, N.Y. (PI numbers), C.M. Rick Tomato Genetics Resource Center, University of California, Davis (LA numbers, UCT5, and Edkawy), and R.G. Gardner, North Carolina State University, Fletcher, N.C. (NC84173). Large quantities of seed were produced by growing and self-pollinating (or sib-mating) plants in the field at The Pennsylvania State University Research Farm, Rock Springs, Pa. (referred to as the Penn State Farm). Due to the presence of self-incompatibility, each accession of L. hirsutum Humb. and Bonpl. was pollinated manually with bulked pollen from 10 sibling plants of the same accession. Care was taken to produce seeds of similar physiological age and quality for all accessions.

EvaluATION OF GERMINATION. Sterile germination medium $(0.8 \%$ agar) was prepared and poured into $15-\mathrm{cm}$ petri plates. Seeds were surface-sterilized with $0.5 \% \mathrm{NaOCl}$ solution for $10 \mathrm{~min}$, rinsed with sterile, distilled water several times and briefly blotted. Seed of $L$. cheesmanii Riley were treated by soaking in $2.7 \% \mathrm{NaOCl}$ for $30 \mathrm{~min}$ to remove seed coat dormancy before sowing (C.M. Rick, personal communication). Seeds were plated onto petri plates under aseptic conditions. Each petri plate contained 80 seeds of one accession (one replication). Two replicates of each accession were used per treatment. Petri plates were arranged in completely randomized designs in incubators maintained in darkness at either $11 \pm 0.5^{\circ} \mathrm{C}$ (cold stress) or $20 \pm 0.5^{\circ} \mathrm{C}$ (control) (seeds were exposed to light only during data collection).

The germination response was scored visually, as radicle protrusion, at 8-h intervals for 37 consecutive days. When calculating the time to germination, seeds that germinated within an interval were presumed to have germinated at the midpoint of that interval. Seeds that failed to germinate in the control (nonstress) treatment were assumed to be nonviable. Thus, the percentage of nonviable seeds was determined from the control treatment. Above this percentage, seeds that failed to germinate in the cold-stress treatment were included in the analysis as right-censored observations (i.e., seeds that presumably were viable but failed to germinate by the last observation time; see statistical analysis below). Hence, the sample size for each replicate was the number of viable seeds, not the number of seeds that were sown or germinated. All experiments were conducted three times, and thus a total of six replicates, equivalent to a maximum of 480 seeds per accession and treatment were used.

Median germination time for each accession was estimated by survival analysis (Gehan, 1969; Lee, 1980). This is a nonparametric procedure that measures time to percentage germination and pro- vides estimates of descriptive statistics for responses over time. These statistics include the number of seeds exposed to risk (potentially able to germinate), the number germinated, and the number withdrawn (i.e., censored observations due to contamination or lack of germination of viable seeds by the end of experiment). The median time in days to $50 \%$ germination (T50) was derived from this analysis for each replicate and was averaged over the six replicates to estimate median germination response $\pm \mathrm{SE}$ for each accession.

Analysis of variance (ANOVA) was used to detect differences among accessions in each treatment. For each accession, CT during germination was measured as the inverse of the ratio of germination time (T50) under cold stress to germination time under control conditions. This index, referred to as "germination tolerance index" $\left(\mathrm{TI}_{\mathrm{G}}\right)$, is a measure of relative CT of a genotype: the larger the index, the higher the tolerance (Rawson et al., 1988). Pearson's correlation analysis (Steel and Torrie, 1980) determined phenotypic correlation coefficients for the various germination parameters.

Evaluation OF VEgETATIVE GROWTH. Seeds were surface sterilized with $0.5 \% \mathrm{NaOCl}$, rinsed with tap water and sown in greenhouse seedling trays containing a medium of 1 peat : 1 perlite : 1 vermiculite $(\mathrm{v} / \mathrm{v})$. Plants were grown in a greenhouse with days/ nights of $\approx 28 / 18{ }^{\circ} \mathrm{C}$ and a daily average irradiance of $400 \pm 50$ $\mathrm{mmol} \cdot \mathrm{m}^{-2} \cdot \mathrm{s}^{-1}$. Plants were fertigated using commercial recommendations for tomato (Jones, 1999). Seedlings 3 to 4 weeks old were transplanted into $1-\mathrm{L}$ pots containing the same growing medium (sowing dates of different accessions were adjusted in order to have seedlings of similar size at the time of transplantation). Three days later, plants were transferred to two walk-in growth chambers with $12 \mathrm{~h}$ days $/ 12 \mathrm{~h}$ nights of either $12 / 5^{\circ} \mathrm{C}$ (cold-stress treatment) or $28 /$ $18^{\circ} \mathrm{C}$ (control treatment). In both chambers, a $12 \mathrm{~h}$ photoperiod was provided with a photosynthetic photon flux of about $350 \mathrm{mmol} \cdot \mathrm{m}^{-}$ ${ }^{2} \cdot \mathrm{s}^{-1}$ and a relative humidity of about $50 \%$. In each growth chamber, plants were arranged in a randomized complete block design with six plants per accession and treatment. For each of the two temperature treatments, plants were grown for 4 weeks before they were individually harvested for shoot (leaf + stem) fresh weight (FW) determination. The harvested tissue was oven-dried at $85^{\circ} \mathrm{C}$ for 10 $\mathrm{d}$, and shoot dry weight (DW) of individual plants determined. The experiments were conducted three times. Thus, a total of 18 plants per accession and treatment was used.

Accession means and variances were determined for samples within each replicate and pooled over replications. Because the results of the three experiments carried out in different times were similar, the data were pooled and reanalyzed. ANOVA was used to determine the significance of differences among accessions in each treatment. For each accession, CT during vegetative growth was defined as the ratio of shoot FW or DW under cold stress to shootFW or DW under control conditions, respectively, and referred to as vegetative growth tolerance index $\left(\mathrm{TI}_{\mathrm{VG}}\right)$. This measure is independent of plant size (plant vigor), and was suggested previously as a useful measure of physiological stress tolerance (Rawson et al., 1988; Rosielle and Hamblin, 1981). Pearson's correlation analysis (Steel and Torrie, 1980) estimated the correlation coefficients for different traits using mean values for the different accessions.

RELATIONSHIP BETWEEN GERMINATION AND VEGETATIVE GROWTH. Pearson's correlation analysis determined phenotypic relationship between the various germination and vegetative growth parameters in the control and cold-stress treatments. Correlation coefficients $(r)$ were calculated based on accession means (or tolerance indices) over replications. Rank correlation coefficients $\left(r_{R}\right)$ were also calculated based on rank order of accessions for different traits. The 
significance of correlation coefficients was determined using the table of correlation coefficients (Steel and Torrie, 1980).

\section{Results}

RESPONSE TO COLD STRESS DURING SEED GERMINATION. Time to $50 \%$ germination ( $\mathrm{T} 50$ ) in the control treatment ranged from 1.17 to $5.75 \mathrm{~d}$ with a mean of 2.84 (Table 1). In all accessions, germination time increased in response to cold stress, however, there were significant variation among accessions. Under cold stress, the T50 ranged from 3.75 to $>37 \mathrm{~d}$ with a mean of 8.89 (Table 1). Across accessions, germination under cold stress was positively correlated $(r=0.82, P<0.01)$ with germination under control conditions (Table 2). However, there were differential responses to cold stress, with some accessions exhibiting more CT than others. The germination tolerance index $\left(\mathrm{TI}_{\mathrm{G}}\right)$ of the accessions ranged from 0.15 (highly sensitive) to 0.48 (highly tolerant) with an average of 0.32 .
Several accessions germinated rapidly under both control and cold stress (e.g., L. pimpinellifolium (Jusl.) Mill. LA722 and LA1579), whereas some others germinated slowly under both conditions (e.g., L. hirsutum LA407 and L. esculentum PI237132) (Table 1). In comparison, some accessions germinated rapidly only under control(e.g., L. esculenum PI339914 and NC84173) or under cold stress (e.g., L. hirsutum LA386). Across accessions, there was no correlation $(r=-0.16, P>0.05)$ between T50 under control conditions and the $\mathrm{TI}_{\mathrm{G}}$, but there was a significant correlation $(r=-0.59, P<0.01)$ between $\mathrm{T} 50$ under cold and the $\mathrm{TI}_{\mathrm{G}}$ (Table 2). In most cases, each accession could be regarded as being either cold tolerant or cold sensitive based on both the T50 under cold stress and the $\mathrm{TI}_{\mathrm{G}}$. For example, L. hirsutum accessions PI127826 and LA1393 and L. pimpinellifolium accessions LA722 and LA1579 were cold tolerant whereas L. hirsutum accessions LA407 and LA1624, L. esculentum accessions PI303726 and PI237132, and breeding line NC84173 were cold sensitive based on both criteria. In contrast, L. esculentum

Table 1. Days to 50\% germination (T50 \pm SE) and shoot dry weight (DW) (g/plant \pm SE) of Lycopersicon accessions in the control and cold-stress treatments. Values in parentheses are the rank order of accessions in each column. Germination under control conditions was not ranked because of identical T50s for many accessions.

\begin{tabular}{|c|c|c|c|c|c|c|c|c|c|}
\hline \multirow[b]{2}{*}{ Accession } & \multirow[b]{2}{*}{ Species } & \multirow[b]{2}{*}{ Cultivar name } & \multirow{2}{*}{$\begin{array}{l}\text { Geographical } \\
\text { origin }\end{array}$} & \multicolumn{3}{|c|}{ Germination (T50 $\pm \mathrm{SE}$ ) } & \multicolumn{3}{|c|}{ Shoot DW (g/plant \pm SE) } \\
\hline & & & & Control & Cold stress & $\mathrm{TI}_{\mathrm{G}}{ }^{2}$ & Control & Cold stress & $\mathrm{TI}_{\mathrm{VG}}{ }^{\mathrm{y}}$ \\
\hline Edkawy & L. esculentum & Edkawy & Egypt & $3.67 \pm 0.17$ & $10.33 \pm 0.37(24)$ & $0.35(13)$ & $4.42 \pm 0.74(15)$ & $0.97 \pm 0.24(21)$ & $0.22(26)$ \\
\hline LA386 & L. hirsutum & & Peru & $3.17 \pm 0.00$ & $7.75 \pm 0.12(15)$ & $0.41(5)$ & $3.89 \pm 0.31(21)$ & $1.31 \pm 0.24(12)$ & $0.34(4)$ \\
\hline LA407 & L. hirsutum & & Ecuador & $3.50 \pm 0.00$ & $15.92 \pm 1.42(29)$ & $0.22(28)$ & $3.16 \pm 0.39(26)$ & $0.81 \pm 0.25(25)$ & $0.26(17)$ \\
\hline LA716 & L. pennellii & & Peru & $2.83 \pm 0.00$ & $7.83 \pm 0.17(16)$ & $0.36(8)$ & $1.79 \pm 0.41(30)$ & $0.59 \pm 0.08(28)$ & $0.33(6)$ \\
\hline LA722 & L. pimpinellifolium & & Peru & $1.67 \pm 0.00$ & $3.75 \pm 0.12(1)$ & $0.44(2)$ & $3.74 \pm 0.48(22)$ & $0.76 \pm 0.14(26)$ & $0.20(27)$ \\
\hline LA1044 & L. cheesmanii & & Ecuador & $5.42 \pm 0.12$ & $33.65 \pm 0.54(30)$ & $0.16(29)$ & $1.62 \pm 0.36(31)$ & $0.19 \pm 0.05(31)$ & $0.12(31)$ \\
\hline LA1310 & $\begin{array}{l}\text { L. esculentum } \\
\text { (var. cerasiforme) }\end{array}$ & & Peru & $3.58 \pm 0.12$ & $10.50 \pm 0.50(25)$ & $0.34(15)$ & $4.61 \pm 0.80(12)$ & $0.56 \pm 0.09(29)$ & $0.12(30)$ \\
\hline LA1393 & L. hirsutum & & Peru & $2.42 \pm 0.12$ & $5.92 \pm 0.12(8)$ & $0.41(4)$ & $2.81 \pm 0.47$ (28) & $0.70 \pm 0.10$ & $0.25(21)$ \\
\hline LA1579 & L. pimpinellifolium & & Peru & $2.33 \pm 0.00$ & $4.84 \pm 0.16(3)$ & $0.48(1)$ & $3.21 \pm 0.20(25)$ & $0.48 \pm 0.13(30)$ & $0.15(29)$ \\
\hline LA1624 & L. hirsutum & & Ecuador & $5.75 \pm 0.12$ & $>37^{x}(31)$ & $(31)$ & $4.69 \pm 0.27(10)$ & $0.91 \pm 0.28(22)$ & $0.19(28)$ \\
\hline LA1777 & L. hirsutum & & Peru & $2.00 \pm 0.00$ & $5.83 \pm 0.24(7)$ & $0.34(14)$ & $3.38 \pm 0.62(24)$ & $1.25 \pm 0.30(14)$ & $0.37(2)$ \\
\hline NC84173 & L. esculentum & & USA & $2.33 \pm 0.00$ & $10.58 \pm 0.42(27)$ & $0.22(27)$ & $4.18 \pm 0.53(19)$ & $0.97 \pm 0.22(20)$ & $0.23(25)$ \\
\hline PI120256 & L. esculentum & & Turkey & $2.25 \pm 0.12$ & $6.42 \pm 0.12(10)$ & $0.35(11)$ & $5.65 \pm 0.40$ & $1.80 \pm 0.50$ & $0.32(7)$ \\
\hline PI127826 & L. hirsutum & & Peru & $2.17 \pm 0.00$ & $5.33 \pm 0.12(5)$ & $0.41(3)$ & $3.63 \pm 0.79(23)$ & $1.43 \pm 0.31(8)$ & $0.39(1)$ \\
\hline PI174261 & L. esculentum & & Turkey & $2.33 \pm 0.00$ & $7.08 \pm 0.12(12)$ & $0.33(16)$ & $5.16 \pm 0.31(6)$ & $1.61 \pm 0.34(3)$ & $0.31(8)$ \\
\hline PI174263 & L. esculentum & & Turkey & $2.00 \pm 0.00$ & $5.17 \pm 0.12$ & $0.39(6)$ & $5.92 \pm 0.62(1)$ & $2.03 \pm 0.60(1)$ & $0.34(3)$ \\
\hline PI201773 & L. esculentum & Earlinorth & Canada & $1.50 \pm 0.00$ & $5.33 \pm 0.94(6)$ & $0.28(22)$ & $4.43 \pm 0.96(14)$ & $1.13 \pm 0.34(16)$ & $0.25(19)$ \\
\hline PI237132 & L. esculentum & Genovese & Italy & $3.33 \pm 0.17$ & $13.25 \pm 0.64(28)$ & $0.25(26)$ & $5.76 \pm 0.93(2)$ & $1.45 \pm 0.21(7)$ & $0.25(18)$ \\
\hline PI280597 & L. esculentum & Mamiliutka & Ukraine & $2.67 \pm 0.00$ & $8.83 \pm 0.17(18)$ & $0.30(20)$ & $5.37 \pm 0.61(5)$ & $1.55 \pm 0.37(6)$ & $0.29(13)$ \\
\hline PI288069 & L. esculentum & Open Air & England & $2.67 \pm 0.17$ & $9.33 \pm 0.17(21)$ & $0.29(21)$ & $5.69 \pm 0.78$ & $1.38 \pm 0.25(10)$ & $0.24(22)$ \\
\hline PI303726 & L. esculentum & Earlinorth & Canada & $2.67 \pm 0.00$ & $10.50 \pm 0.50(26)$ & $0.25(25)$ & $4.29 \pm 0.66(17)$ & $1.23 \pm 0.34(15)$ & $0.29(14)$ \\
\hline PI339914 & L. esculentum & Cold Set & Canada & $1.17 \pm 0.00$ & $8.00 \pm 0.92(17)$ & $0.15(30)$ & $4.39 \pm 1.29(16)$ & $1.36 \pm 0.43(11)$ & $0.31(11)$ \\
\hline PI341984 & L. esculentum & & USA & $2.33 \pm 0.00$ & $6.58 \pm 0.26(11)$ & $0.35(12)$ & $4.89 \pm 0.82(9)$ & $1.29 \pm 0.42(13)$ & $0.26(16)$ \\
\hline PI341985 & L. esculentum & & USA & $2.33 \pm 0.00$ & $7.08 \pm 0.12(13)$ & $0.33(17)$ & $5.15 \pm 0.60(7)$ & $1.59 \pm 0.26(4)$ & $0.31(9)$ \\
\hline PI341988 & L. esculentum & & USA & $2.33 \pm 0.00$ & $6.08 \pm 0.12(9)$ & $0.38(7)$ & $4.64 \pm 0.44(11)$ & $1.38 \pm 0.31(9)$ & $0.30(12)$ \\
\hline PI370080 & L. esculentum & Sub-Arctic Delight & Canada & $1.17 \pm 0.00$ & $4.50 \pm 0.24$ (2) & $0.26(24)$ & $3.11 \pm 0.77(27)$ & $0.83 \pm 0.29(24)$ & $0.27(15)$ \\
\hline PI370087 & L. esculentum & & Canada & $2.92 \pm 0.12$ & $9.33 \pm 0.60(20)$ & $0.31(19)$ & $4.55 \pm 1.03(13)$ & $1.05 \pm 0.25(17)$ & $0.23(24)$ \\
\hline PI370088 & L. esculentum & Farthest North & Canada & $2.50 \pm 0.00$ & $9.25 \pm 1.69$ (19) & $0.27(23)$ & $5.03 \pm 0.67(8)$ & $1.55 \pm 0.56(5)$ & $0.31(10)$ \\
\hline PI390660 & L. hirsutum & & Peru & $2.50 \pm 0.00$ & $7.67 \pm 0.53$ & $0.33(18)$ & $4.11 \pm 0.33(20)$ & $1.04 \pm 0.34(18)$ & $0.25(20)$ \\
\hline PI390663 & L. hirsutum & & Peru & $3.58 \pm 0.12$ & $9.83 \pm 0.17(22)$ & $0.36(9)$ & $2.55 \pm 0.62(29)$ & $0.86 \pm 0.19(23)$ & $0.34(5)$ \\
\hline UCT5 & L. esculentum & & USA & $3.58 \pm 0.12$ & $10.08 \pm 0.12(23)$ & $0.36(10)$ & $4.23 \pm 0.92(18)$ & $1.01 \pm 0.25(19)$ & $0.24(23)$ \\
\hline Mean & & & & $2.84 \pm 1.15$ & $8.89 \pm 5.31$ & 0.32 & $4.22 \pm 1.08$ & $1.17 \pm 0.45$ & 0.27 \\
\hline
\end{tabular}

${ }^{\mathrm{z}}$ Germination tolerance index $\left(\mathrm{TI}_{\mathrm{G}}\right)$, calculated as the inverse of the ratio of T50 under cold-stress to T50 under control conditions. Accessions were ranked on the basis of $\mathrm{TI}_{\mathrm{G}}$. For accessions with identical $\mathrm{TI}_{\mathrm{G}}$, $\mathrm{T} 50$ under cold stress was used as a secondary ranking parameter.

${ }^{\mathrm{y}}$ Vegetative growth tolerance index $\left(\mathrm{TI}_{\mathrm{VG}}\right)$, calculated as the ratio of DW under cold stress $\left(\mathrm{DW}_{\mathrm{S}}\right)$ to DW under control conditions $\left(\mathrm{DW} \mathrm{C}_{\mathrm{C}}\right)$. Accessions were ranked on the basis of $\mathrm{TI}_{\mathrm{VG}}$. For accessions with identical $\mathrm{TI}_{\mathrm{VG}}, \mathrm{DW}_{\mathrm{S}}$ was used as a secondary ranking parameter.

${ }^{x}$ Did not reach $50 \%$ germination at $37 \mathrm{~d}$. 
Table 2. Estimates of phenotypic correlations between various germination and vegetative growth parameters for tomato accessions evaluated under control and cold-stress conditions. Values in parentheses are rank correlation coefficients $\left(r_{R}\right)$.

\begin{tabular}{|c|c|c|c|c|c|}
\hline \multirow[b]{2}{*}{ Parameter } & \multicolumn{2}{|c|}{ Germination } & \multicolumn{3}{|c|}{ Vegetative growth } \\
\hline & Cold stress & $\mathrm{TI}_{\mathrm{G}}{ }^{\mathrm{z}}$ & Control & Cold stress & $\mathrm{TI}_{\mathrm{VG}}^{\mathrm{y}}$ \\
\hline \multicolumn{6}{|l|}{ Germination } \\
\hline Control & $0.82^{* *}$ & -0.16 & -0.20 & $-0.41^{*}$ & $-0.47^{* *}$ \\
\hline Cold stress & & $-0.59^{* *}\left(0.64^{* *}\right)$ & $-0.33(-0.06)$ & $-0.42^{*}(0.19)$ & $-0.47^{* *}\left(0.37^{*}\right)$ \\
\hline $\mathrm{TI}_{\mathrm{G}}^{\mathrm{z}}$ & & & $-0.02(-0.17)$ & $0.02(0.02)$ & $0.14(0.26)$ \\
\hline \multicolumn{6}{|c|}{ Vegetative growth } \\
\hline Control & & & & $0.80^{* *}\left(0.77^{* * *}\right)$ & $0.14(0.09)$ \\
\hline Cold stress & & & & & $0.68^{* *}\left(0.63^{* * *}\right)$ \\
\hline
\end{tabular}

${ }^{\mathrm{z}}$ Germination tolerance index $\left(\mathrm{TI}_{\mathrm{G}}\right)$, calculated as the inverse of the ratio of T50 under cold-stress to T50 under control conditions.

${ }^{\mathrm{y}}$ Vegetative growth tolerance index $\left(\mathrm{TI}_{\mathrm{VG}}\right)$, calculated as the ratio of $\mathrm{DW}$ under cold stress $\left(\mathrm{DW}_{\mathrm{S}}\right)$ to $\mathrm{DW}$ under control conditions $\left(\mathrm{DW} \mathrm{C}_{\mathrm{C}}\right)$.

,*** Significant at $P<0.05$ or 0.01 , respectively.

accession PI370080 was highly cold tolerant based on T50 under cold stress but exhibited low $\mathrm{TI}_{\mathrm{G}}$ (due to extremely rapid germination under control conditions).

RESPONSE TO COLD STRESS DURING VEGETATIVE GROWTH. Because results were similar for FW and DW, only the results for DW are presented and discussed. Across accessions, DW under control conditions $\left(\mathrm{DW}_{\mathrm{C}}\right)$ ranged from 1.79 to $5.92 \mathrm{~g} /$ plant with a mean of 4.22 (Table 1). Growth of all accessions was reduced in response to cold stress; however, there was significant genotypic variation (Table 1). Across accessions, DW under cold stress $\left(\mathrm{DW}_{\mathrm{S}}\right)$ ranged from 0.48 to $2.03 \mathrm{~g} /$ plant with a mean of 1.17 (Table 1). There was a positive correlation $(r=0.80, P<0.01)$ between $\mathrm{DW}_{\mathrm{C}}$ and $\mathrm{DW}_{\mathrm{S}}$, indicating that growth under cold stress was influenced by plant vigor. To remove the confounding effect of plant vigor, CT was defined and measured as the ratio of $\mathrm{DW}_{\mathrm{S}}$ to $\mathrm{DW}_{\mathrm{C}}$ and referred to as physiological CT or vegetative growth tolerance index $\left(\mathrm{TI}_{\mathrm{VG}}\right)$. Correlation analysis indicated that this measure of cold tolerance $\left(\mathrm{TI}_{\mathrm{VG}}\right)$ was independent of plant vigor, as judged by the absence of a significant correlation $(r=0.14, P>0.05)$ between $\mathrm{TI}_{\mathrm{VG}}$ and DW (Table 2). Across accessions, there was a positive correlation ( $r=$ $0.68, P<0.01)$ between $\mathrm{DW}_{\mathrm{S}}$ and $\mathrm{TI}_{\mathrm{VG}}$, indicating the presence of accessions with high vigor and high CT (such as L. esculentum accessions PI174263 and PI120256 and L. hirsutum accessions PI127826, LA1777, and LA386) (Table 1).

Across accessions, $\mathrm{TI}_{\mathrm{VG}}$ ranged from 0.12 (cold sensitive) to 0.39 (cold tolerant) indicating the presence of genotypic variation for CT during vegetative growth (Table 1 ). The L. hirsutum accessions native to high elevations in Peru, including PI127826 (elevation $3000 \mathrm{~m}), \mathrm{LA} 1777$ (3200 m), LA386 (3000 m) and PI390663 (2300 m), exhibited the highest CT, whereas $L$. pimpinellifolium accessions LA722 and LA1579, L. cheesmanii accession LA1044 and L. esculentum var. cerasiforme accession LA1310 exhibited the lowest CT (Table 1). Several L. esculentum accessions, including PI174263 and PI120256, also exhibited high CT.

RELATIONSHIP BETWEEN COLD TOLERANCE DURING SEED GERMINATION AND VEGETATIVE GROWTH. Accessions that were cold tolerant during seed germination were not necessarily cold tolerant during vegetative growth. Linear correlation analyses indicated that there was no significant rank correlation between germination time (T50) and dry matter production $\left(\mathrm{DW}_{\mathrm{S}}\right)$ under cold stress $\left(r_{R}=0.19, P>\right.$ $0.05)$ or between $\mathrm{TI}_{\mathrm{G}}$ and $\mathrm{TI}_{\mathrm{VG}}\left(r_{R}=0.26, P>0.05\right)$. However, there were some accessions that were either cold tolerant or cold sensitive during both seed germination and vegetative growth; this resulted in a weak correlation $(r=-0.42, P<0.05)$ between T50 and dry matter production under cold stress (Table 2).

\section{Discussion}

STAGE-SPECIFIC RESPONSE TO COLD STRESS. There was little or no phenotypic relationship between CT during seed germination and vegetative growth in the accessions evaluated. Lack of relationship was evident based on both absolute and relative (physiological) CT of the accessions. It is likely that different genetic and physiological mechanisms control CT during seed germination and vegetative growth. Absence of genetic relationships between different developmental stages was reported previously for other stress-related traits. For example, Johnson et al. (1992) determined that in alfalfa (Medicago sativa L.) there was no phenotypic or genetic relationship between plant performance under salt stress in different growth stages. Similar results were reported for salt tolerance in tomato (Foolad, 1999; Foolad and Lin, 1997) and slender wheatgrass [Elymus trachycalus spp. trachycalus (Link) Malte] (Pearen et al., 1997). The implication of these findings is that, for development of stress tolerant plants, it may be necessary to evaluate each and every stage of plant development for assessment of tolerance and the identification and utilization of useful genetic components.

A few accessions, however, were identified with CT during both seed germination and vegetative growth. Examples are L. hirsutum PI127826 and LA1777 and L. esculentum PI174263 and PI120256 (Table 1). Whether in these accessions identical genes control CT during the two stages could not be determined in this study. In previous germplasm evaluation research, we identified a few tomato accessions, including PI174263 (L. esculentum) and LA722 (L. pimpinellifolium), with salt tolerance (ST) during both seed germination and vegetative growth. Subsequent investigations, including analyses of the response and correlated response to selection for ST (Foolad and Lin, 1997) and genetic mapping of quantitative trait loci (QTLs) at each stage (Foolad, 1999), indicated that ST during germination in these accessions was genetically independent of ST during vegetative growth. Similarly, more recently we investigated genetic control of CT in the L. esculentum accession PI120256 during both seed germination (Foolad and Lin, 1998) and vegetative growth (Foolad and Lin, unpublished). By analysis of response and correlated response to selection, it was determined that CT during vegetative growth was genetically independent of CT during seed germination (Foolad and Lin, unpublished). However, precise determination of the nature of the genetic relationship between $\mathrm{CT}$ at different developmental stages requires identification, genetic mapping, cloning, and characterization of functional genes conferring tolerance at each stage.

Absolute Versus Relative cold tolerance. Plant response to cold stress can be measured in either absolute or relative terms. For 
example, CT during seed germination may be defined by the germination time (e.g., T50) under cold stress (a measure of absolute CT) or by the increase in the germination time under cold-stress relative to control conditions (relative $\mathrm{CT}$ or germination tolerance index, $\mathrm{TI}_{\mathrm{G}}$ ). Similarly, CT during vegetative growth may be measured either as the amount of dry matter produced under cold stress $\left(\mathrm{DW}_{\mathrm{S}}\right.$, absolute $\left.\mathrm{CT}\right)$ or as the relative decrease in dry matter production under cold stress (relative $\mathrm{CT}$ or vegetative growth tolerance index, $\mathrm{TI}_{\mathrm{VG}}$ ). While $\mathrm{TI}_{\mathrm{G}}$ and $\mathrm{TI}_{\mathrm{VG}}$ are good measures of physiological CT, solely they may not be useful for breeding purposes. For example, a genotype that germinates rapidly under cold stress but exhibits a small $\mathrm{TI}_{\mathrm{G}}$ may be more useful than a genotype that exhibits large $\mathrm{TI}_{\mathrm{G}}$ but germinates slowly under both control and cold-stress conditions (e.g., L. hirsutum PI390663). Ideal genotypes are those with rapid germination under cold stress and with high $\mathrm{TI}_{\mathrm{G}}$ (e.g., L. hirsutum PI127826 or LA1777 and $L$. esculentum PI174263). Similarly, CT breeding during vegetative growth must be based on consideration of both absolute and relative CT criteria. Dry matter production under cold stress $\left(\mathrm{DW}_{\mathrm{S}}\right)$ is a function of both plant vigor and physiological CT. Some accessions may exhibit large $\mathrm{DW}_{\mathrm{S}}$ mainly because of high growth potential (high vigor). Genes contributing to plant vigor may be different from genes conferring stress tolerance (Forster et al., 1990). Thus, $\mathrm{DW}_{\mathrm{S}}$ alone may not be a good selection criterion when breeding for $\mathrm{CT}$ during vegetative growth. Similarly, $\mathrm{TI}_{\mathrm{VG}}$ alone may not be good either because a genotype may exhibit large $\mathrm{TI}_{\mathrm{VG}}$ but does not grow much in either control or cold-stress treatment (e.g., L. pennellii LA716 and L. hirsutum PI390663). When breeding for efficient production under cold stress, genes for both plant vigor and $\mathrm{CT}$ are important. Thus, accessions PI174263 and PI120256(L. esculentum) and PI127826, LA1777, and LA386 (L. hirsutum) that exhibit high $\mathrm{TI}_{\mathrm{VG}}$ and high $\mathrm{DW}_{\mathrm{S}}$ should be useful for CT breeding in tomato.

USEFUL GERMPLASMS FOR COLD TOLERANCE BREEDING. The cold tolerant accessions identified in this study can be classified into three groups. First, those that exhibited CT during seed germination, including L. pimpinellifolium LA722 and LA1579, L. hirsutum PI127826, LA1777, and LA1393, and L. esculentum PI370080, PI201773, PI174263, and PI120256. These accessions should be useful resources for breeding tomatoes for direct seeding. Second, those that exhibited CT during vegetative growth, including $L$. hirsutum PI127826, LA1777, and LA386, and L. esculentum PI174263 and PI120256. Cold tolerance during vegetative growth is particularly important for crop establishment during early season in temperate regions. Third, those that exhibited CT during both seed germination and vegetative growth, including $L$. hirsutum PI127826 and LA1777, and L. esculentum PI174263 and PI120256. However, for practical breeding purposes, it may be desirable to identify accessions that exhibit CT during all stages of plant development, including reproduction (e.g., flowering, fruit set and ripening under low temperatures). Cold tolerance during reproduction is of interest, particularly for greenhouse production in northern regions and field growing conditions in the far north. Further investigations are needed to determine CT of these accessions during reproduction and to examine the relationship between tolerance during reproduction and earlier stages.

\section{Literature Cited}

Cannon, O.S., D.M. Gatherum, and W.G. Miles. 1973. Heritability of low temperature seed germination in tomato. HortScience 8:404-405.

Dahal, P. and K.J. Bradford. 1990. Effects of priming and endosperm integrity on seed germination rates of tomato genotypes: II. Germination at reduced water potential. J. Expt. Bot. 41:1441-1453.
DeVos, D.A., J.R.R. Hill, R.W. Helper, and D.L. Garwood. 1981. Inheritance of low temperature sprouting ability in $\mathrm{F}_{1}$ tomato crosses. J. Amer. Soc. Hort. Sci. 106:352-355.

DeVos, D.A., J.R.R. Hill, R.W. Helper, and D.L. Garwood. 1982. Diallel analysis of low temperature sprouting ability in tomato populations evaluated in field and laboratory environments. Can. J. Genet. Cytol. 24:787-796.

Dickson, M.H. and R. Petzoldt. 1987. Inheritance of low temperature tolerance in beans at several growth stages. HortScience 22:481-483.

El-Sayed, M.N. and C.A. John. 1973. Heritability studies of tomato emergence at different temperatures. J. Amer. Soc. Hort. Sci. 98:440-443.

Foolad, M.R. 1999. Comparison of salt tolerance during seed germination and vegetative growth in tomato by QTL mapping. Genome 42:727-734.

Foolad, M.R., F.Q. Chen, and G.Y. Lin. 1998. RFLP mapping of QTLs conferring cold tolerance during germination in an interspecific cross of tomato. Mol. Breeding 4:519-529.

Foolad,M.R. and G.Y.Lin. 1997. Absence of a relationship between salt tolerance during germination and vegetative growth in tomato. Plant Breeding 116:363-367.

Foolad, M.R. and G.Y. Lin. 1998. Genetic analysis of low temperature tolerance during germination in tomato, Lycopersicon esculentum Mill. Plant Breeding 117:171-176.

Forster, B.P., M.S. Phillips, T.E. Miller, E. Baird, and W. Powell. 1990. Chromosome location of genes contolling tolerance to salt $(\mathrm{NaCl})$ and vigor in Hordeum vulgare and $H$. chilense. Heredity 65:99-107.

Gehan, E.A. 1969. Estimating survival functions from the life table. J. Chron. Dis. 21:629-644.

Graham, D. and B.R. Patterson. 1982. Responses of plants to low, nonfreezing temperatures: proteins, metabolism, and acclimation. Annu. Rev. Plant Physiol. 33:347-372.

Johnson, D.W., S.E. Smith, and A.K. Dobrenz. 1992. Genetic and phenotypic relationships in response to $\mathrm{NaCl}$ at different developmental stages in alfalfa. Theor. Appl. Genet. 83:833-838.

Jones, Jr., J.B. 1999. Tomato plant culture-In the field, greenhouse, and home garden. NCRC Press, New York.

Lee, E. 1980. Statistical methods for survival data analysis. Wadworth, Lifetime Learning Publ., Belmont, Calif.

Lyons, J.M. 1973. Chilling injury in plants. Annu. Rev. Plant Physiol. 24:445-466.

Lyons, J.M., D. Graham, and J.K. Raison (eds.). 1979. Low temperature stress in crop plants, the role of the membrane. Academic Press, New York.

Ng, T.J. and E.C. Tigchelaar. 1973. Inheritance of low temperature seed sprouting in tomato. J. Amer. Soc. Hort. Sci. 98:314-316.

Patterson, B.D., L. Mutton, R.E. Paull, and V.Q. Nguyen. 1987. Tomato pollen development: Stages sensitive to chilling and a natural environment for the selection of resistant genotypes. Plant Cell Environ. 10:363-368.

Patterson, B.D., R. Paull, and R.M. Smillie. 1978. Chilling resistance in Lycopersicon hirsutum Humb. \& Bonpl., a wild tomato with a wide altitudinal distribution. Austral. J. Plant Physiol. 5:609-617.

Pearen, J.R., M.D. Pahl, M.S. Wolynetz, and R. Hermesh. 1997. Association of salt tolerance at seedling emergence with adult plant performance in slender wheatgrass. Can. J. Plant Sci. 77:81-89.

Rawson, H.M., R.A. Richards, and R. Munns. 1988. An examination of selection criteria for salt tolerance in wheat, barley and triticale genotypes. Austral. J. Agr. Res. 39:759-772.

Rosielle, A.A. and J. Hamblin. 1981. Theoretical aspects of selection for yield in stress and non-stress environments. Crop Sci. 21:943-946.

Scott, S.J. and R.A. Jones. 1982. Low temperature seed germination of Lycopersicon species evaluated by survival analysis. Euphytica 31:869-883.

Scott, S.J. and R.A. Jones. 1985. Cold tolerance in tomato. I. Seed germination and early seedling growth of Lycoperscion esculentum. Physiol. Plant. 65:487-492.

Scott, S.J. and R.A. Jones. 1986. Cold tolerance in tomato: II. Early seedling growth of Lycopersicon sp. Physiol. Plant. 66:659-663.

Smith, P.G. and R.H. Millet. 1964. Germinating and sprouting responses of the tomato at low temperatures. Proc. Amer. Soc. Hort. Sci. 84:480-484.

Steel, R.G.D. and J.H. Torrie. 1980. Principles and procedures of statistics. 2nd ed. McGraw-Hill, New York.

Vallejos, C.E. 1979. Genetic diversity of plants for response to low temperature and its potential use in crop plants, p. 473-489. In: J.M. Lyons, D. Graham, and J.K. Raison (eds.). Low-temperature stress in crop plants. Academic Press, New York. Wolf, S., D. Yakir, M.A. Stevens, and J. Rudich. 1986. Cold temperature tolerance of wild tomato species. J. Amer. Soc. Hort. Sci. 111:960-964. 